\title{
COMPATIBILIZAÇÃO DA CAE REV.1 COM A CAE REV.2 - UMA PROPOSTA DE TRABALHO ${ }^{1}$
}

\author{
EDUARDA MARQUES DA COSTA ${ }^{2}$ \\ NUNO MARQUES DA COSTA ${ }^{2}$
}

\begin{abstract}
Resumo - A presente nota pretende apresentar uma proposta de compatibilização da classificação das actividades económicas em vigor desde 1973, CAE-Rev.1, e a actual classificação CAE-Rev.2.

A comparação das duas versões mostra que existem diferenças conceptuais e estruturais, sendo estas mais evidentes nas actividades económicas que maiores alterações sofreram ao longo das duas últimas décadas: A nova classificação apresenta um maior nível de desagregação, especialmente nas actividades relacionadas com o comércio e os serviços.
\end{abstract}

Palavras-chave: Classificação das actividades económicas, classificação de Browning e Singlemann, reestruturação económica

\begin{abstract}
Work Proposal To MaKe Two Classifications Of ECONOMIC ACTIVITIES COMPATIBLE. In this work the new national classification of economic activity is compared with the previous one, in order to use both of them. When the new and the former classification are compared conceptual and structural differences appear, mainly among the economic activities that have emerged in the last two decades. The new classification is more detailed, specially in the trade and service activities, reflecting an adaptation to the new productive system.
\end{abstract}

Key-words: Economic activities Classification, Browning and Singlemann classification, economic changes.

\section{A NECESSIDADE DE COMPATIBILIZAÇÃO}

A presente nota pretende apresentar uma proposta de compatibilização da classificação das actividades económicas em vigor desde 1973, CAE-Rev.1, e a actual classificação CAE-Rev.2.

O novo quadro para a classificação das actividades económicas portuguesas, que se passou a designar por CAE-Rev.2, abreviatura de Classificação Portuguesa das Actividades Económicas, Revisão 2 foi estabelecido pelo Decreto-Lei $n^{\circ}$ 182/93 de 14 de Maio e constitui a segunda alteração da classificação que teve a sua primeira versão em 1964.

\footnotetext{
1 Este trabalho foi efectuado no âmbito do projecto «Desenvolvimento industrial e território», JNICT, PCSH/C/GEO/715/93.

2 Assistentes da Universidade de Lisboa. Investigadores do CEG. Centro de Estudos Geográficos, Faculdade de Letras de Lisboa, Cidade Universitária, 1699 LISBOA Codex. Tel: (351-1) 79402 18; Fax: (351-1) 79386 90. e-mail: ceg@mail.telepac.pt.
} 
A versão de 1964 constituiu a primeira classificação adaptada à realidade económica portuguesa, tendo até essa data sido adoptada a Classificação Internacional Tipo de Todos os Ramos de Actividade Económica (CITA), publicada em 1953 e revista em 1961.

A actual revisão da CAE foi determinada por um lado, pela necessidade de adaptação às modificações na estrutura económica portuguesa e internacional ocorridas nas últimas duas décadas, por outro, pela necessidade de compatibilização com as estatísticas internacionais, nomeadamente, as comunitárias (NACE Rev.1 - Nomenclatura Estatística das Actividades Económicas na Comunidade Europeia - Revisão 1). No entanto, há outro aspecto que não se pode negligenciar; as mudanças propostas não podiam inviabilizar a comparação com a versão anterior, o que impediria a realização de estudos evolutivos.

A comparação das duas versões mostra que existem diferenças conceptuais e estruturais, sendo mais evidentes nas actividades económicas que maiores alterações sofreram ao longo das duas últimas décadas (comércio e os serviços). Conceptualmente, a actual classificação baseia-se não tanto nas características físicas do produto final mas sim na função da actividade ou no tipo de uso do produto final. São exemplos a produção de calçado, que na CAE Rev. 1 se encontrava dispersa por quatro sub-ramos ${ }^{3}$ e agora está representada num único; o acabamento de fios e tecidos, que actualmente é classificado num só grupo (17303), independentemente de o produto ser de algodão, lã ou fibra sintética (na anterior CAE pertencentes a sub-ramos distintos); e a publicidade, que actualmente engloba as actividades anteriormente classificadas em serviços de publicidade e produção de tabuletas e outro material publicitário, esta última integrado na indústria transformadora.

Em termos estruturais as modificações evidenciam-se no grau de desagregação das actividades económicas. A actual classificação, ao contrário do que se poderia deduzir dos exemplos anteriores, apresenta um maior grau de diferenciação, existindo actualmente 715 actividades contra as 602 anteriores (nos níveis máximos de desagregação das duas classificações). Esta maior desagregação é particularmente evidente nas actividades de prestação de serviços. O quadro I estabelece a comparação entre as versões de 1973 e de 1991, permitindo evidenciar esta observação.

Quadro I - Comparação entre os níveis de desagregação sectorial da CAE-REV.1 e da CAE-REV.2 Table I - Comparision between CAE-Rev.1 and CAE-Rev.2

\begin{tabular}{|c|c|c|c|c|c|c|c|c|}
\hline & \multicolumn{2}{|c|}{ Alfabético } & \multicolumn{6}{c|}{ Numérico } \\
\hline & Uma letra & Duas letras & $\begin{array}{c}1 \\
\text { dígito }\end{array}$ & 2 dígitos & 3 dígitos & 4 dígitos & 5 dígitos & 6 dígitos \\
\hline CAE-Rev.2 & 17 & 31 & - & 60 & 222 & 503 & 715 & - \\
\hline CAE-Rev.1 & - & - & 10 & 34 & 80 & 201 & 532 & 602 \\
\hline
\end{tabular}

Fonte: INE (1993)

O grau de desagregação patente na presente versão da CAE é mais evidente nas actividades ligadas aos serviços, existindo ainda a introdução de níveis de desagre-

\footnotetext{
3 324-Fabricação de calçado, com excepção do calçado vulcanizado; de borracha moldada ou plástico e o feito inteiramente de madeira

331929-Fabricação de outros artigos de madeira não especificado 355990-Fabricação de artigos diversos de borracha não especificado 356000-Fabricação de artigos de matérias plásticas
} 
gação diferenciados alfabeticamente, o que não acontece com as versões anteriores da CAE. O grau de compatibilidade entre a actual CAE e a NACE-Rev.1 é total até ao nível de desagregação correspondente a quatro dígitos e igual à CITA Rev.3 ao nível de desagregação alfabética, uma letra e comum ao nível de desagregação a dois dígitos.

A maior desagregação procura responder às novas formas de organização do sistema produtivo que emergiram após a crise internacional dos anos setenta. Um dos aspectos mais importantes é a externalização (e terciarização) de muitas funções outrora integradas no sistema de produção industrial das grandes empresas que caracterizaram o pós-guerra. Estas funções passaram a ser desempenhadas por múltiplas empresas de pequena e média dimensão prestadoras de novos serviços que em muito contribuiram para a terciarização da economia. Outro aspecto que explica o aparecimento de novas funções (particularmente as ligadas ao sector terciário) é a crescente globalização do sistema mundial. Esta assume expressão na internacionalização dos fluxos comerciais e financeiros, na valorização das vantagens competitivas de cada país/região, no aumento da concorrência internacional e na difusão das novas formas de comunicação.

Assim, algumas actividades que, na anterior versão da CAE, estavam integradas em ramos de produção industrial, surgem agora individualizadas. É o caso da «manutenção e reparação de máquinas de escritório, de contabilidade e de material informático» (725) que, na anterior versão, estava incluída no ramo da «fabricação de máquinas de escritório e contabilidade e computadores» (382510) e «outros serviços de reparação» (951900).

Por outro lado, individualizaram-se funções que na CAE-Rev.1 estavam integradas num único grupo - «serviços prestados às empresas, com excepção de aluguer de máquinas e equipamento» (832900). Entre estas contam-se: «consultoria e programação informática» (72200), «actividades de bancos de dados» (72400), «actividades de consultoria para os negócios e a gestão» (74140), «actividades das sociedades gestoras de participações sociais» (74150), «selecção e colocação de pessoal» (74500), «actividades de investigação e segurança» (74600), «actividades de limpeza industrial» (74700), «organização de feiras e exposições» (74841) e as «actividades de agências de notícias» (92400).

Outra mudança que reflecte as novas dinâmicas é a que se verifica no domínio da hotelaria e restauração. A expansão dos serviços de «catering» encontra resposta na sua individualização (outrora estavam integrados no grupo dos cafés, bares, e outros). Outros sub-ramos que aparecem individualizados na actual revisão são os «apartamentos turísticos sem restaurante» (55123), o «turismo em espaço rural» (55233), as «pousadas de juventude e abrigos de montanha» (55210) e as «colónias de férias» (55231). Estes quatro novos grupos estavam integrados numa classe denominada «outros locais de alojamento, n.e.» (632900).

Pelo exposto anteriormente podemos afirmar que a maior desagregação das actividades presente na CAE-Rev.2 permite conhecer melhor as dinâmicas do sistema produtivo actual, nomeadamente a dimensão e as vertentes que assume a terciarização da economia.

\section{UMA PROPOSTA DE TRABALHO}

A publicação do INE, Classificação Portuguesa das Actividades Económicas Tabela de Equivalências, de 1993, apresenta a compatibilização da informação para um elevado nível de desagregação (CAE-REV.1 a seis digitos para CAE-REV.2 a cinco digitos). Na presente nota, propõe-se a compatibilização da 
informação para dois e três digitos (segundo a CAE-REV.1) o que permitirá encontrar grandes grupos como sejam:

- Agricultura, Silvicultura e Pescas

- Indústria Extractiva

- Indústria Transformadora

- Electricidade, Gás e Água

- Construção Civil e Obras Públicas

- Serviços de Distribuição

- Serviços de Apoio à Produção

- Serviços Sociais

- Serviços Pessoais

Estes grupos correspondem a uma adaptação à classificação proposta por Browning e Singelmann em 1975. Esta classificação não apresenta diferenças significativas em relação aos sectores primário e secundário já citados por Fischer e Clark nos anos quarenta, mas em relação ao sector terciário apresenta uma proposta de divisão em quatro grupos, que tem como base o modo como os serviços são consumidos e não tanto como estes são produzidos: serviços de distribuição, de apoio à produção, sociais e pessoais.

Em 1990, ALVES e PIRES apresentaram uma proposta de adaptação da tipologia de Browning e Singelmann às classificações utilizadas nas estatísticas nacionais (Nomenclatura das Contas Nacionais - NCN - e CAE - REV.1). A presente proposta de compatibilização (Quadro II) pretende não só comparar as duas versões da CAE como ainda enquadrar-se na forma de agrupamento proposta por ALVES e PIRES.

Quadro II - Proposta de compatibilização entre a CAE-REV.1 e CAE-REV.2

Table II - Proposal for compatibilisation of CAE-Rev.1 and CAE-Rev.2

a) Agricultura, Silvicultura, Caça e Pesca (a.Primary Sector)

\begin{tabular}{|l|l|}
\hline \multicolumn{1}{|c|}{ CAE REV. 2 } & \multicolumn{1}{c|}{ CAE REV. 1 } \\
\hline $011+012+013+015$ & $\begin{array}{l}11 \text { (Agricultura, pecuária e caça) } \\
\text { (excluindo 112 - serviços relacionados com a } \\
\text { agricultura, excepto serviços de veterinária e } \\
\text { transporte de produtos agrícolas) }\end{array}$ \\
\hline 020 & 12 (Silvicultura e exploração florestal) \\
\hline 050 & 13 (Pesca) \\
\hline
\end{tabular}

b) Indústria Extractiva

(b. Minning)

\begin{tabular}{|l|l|}
\hline \multicolumn{1}{|c|}{ CAE REV. 2 } & \multicolumn{1}{c|}{ CAE REV. 1 } \\
\hline $101+102+103+111+112+120+131+1$ & 2 (Indústria extractiva) \\
$32+141+142+143+144+145$ & \\
\hline
\end{tabular}




\section{c) Indústria Transformadora \\ (c. Manufacturing Industry)}

\begin{tabular}{|c|c|c|}
\hline CAE REV. 2 & & CAE REV. 1 \\
\hline $151+152+153+154+155+156+157+158+(40302)$ & & 311+312 (Indústrias da alimentação) \\
\hline 159 & & 313 (Indústrias das bebidas) \\
\hline 160 & 31 & 314 (Indústrias do tabaco) \\
\hline $171+172+173+174+175+176+177$ & & 321 (Indústrias têxteis) \\
\hline 181+182+183 (excluindo 18301) & & 322 (Indústrias do vestuário) \\
\hline $191+192+(18301)$ & & $\begin{array}{l}323 \text { (Indústrias dos curtumes e dos } \\
\text { artigos de couro) }\end{array}$ \\
\hline 193 & 32 & 324 (Indústrias do calçado) \\
\hline $201+202$ (excluindo 20202$)+203+204+205$ & & 331 (Indústrias da madeira) \\
\hline 361 (excluindo 36142) & 33 & 332 (Indústrias de mobiliário) \\
\hline $211+212+(20202)$ & & 341 (Indústrias do papel) \\
\hline 221+222 (excluindo 2214) & 34 & $\begin{array}{l}342 \text { (Indústrias das artes gráficas e } \\
\text { edição de publicações) }\end{array}$ \\
\hline $233+241+242+247$ & & $\begin{array}{l}351 \text { (Indústrias de produtos químicos } \\
\text { industriais) }\end{array}$ \\
\hline $243+244+245+246$ & & $\begin{array}{l}352 \text { (Indústrias de fabrico de outros } \\
\text { produtos químicos) }\end{array}$ \\
\hline 232 & & $\begin{array}{l}353 \text { (Indústrias de refinação de pe- } \\
\text { tróleo) }\end{array}$ \\
\hline 231 & & $\begin{array}{l}354 \text { (Indústrias de fabricação de de- } \\
\text { rivados do petróleo) }\end{array}$ \\
\hline 251 & & 355 (Indústria da borracha) \\
\hline 252 & 35 & 356 (Indústria dos plásticos) \\
\hline $262+263$ & & $\begin{array}{l}361 \text { (Indústrias de artigos de porce- } \\
\text { lana, faiança e grés }\end{array}$ \\
\hline $261+372$ & & 362 (Indústrias do vidro) \\
\hline $264+265+266+267+268$ & 36 & $\begin{array}{l}369 \text { (Indústrias de outros produtos } \\
\text { minerais não metálicos) }\end{array}$ \\
\hline $271+272+273+275$ (parte) +371 (parte) & & $\begin{array}{l}371 \text { (Indústrias básicas de ferro e } \\
\text { aço) }\end{array}$ \\
\hline $274+275$ (parte)+371(parte) & 37 & $\begin{array}{l}372 \text { (Indústrias básicas de metais não } \\
\text { ferrosos) }\end{array}$ \\
\hline $281+282+283+284+285+286+287+(36142)$ & & $\begin{array}{l}381 \text { (Indústrias de fabricação de } \\
\text { produtos metálicos com excepção de } \\
\text { máquinas, equipamento e material de } \\
\text { transporte) }\end{array}$ \\
\hline $291+292+293+294+295+296+297+300$ & & $\begin{array}{l}382 \text { (Indústrias de fabricação de ma- } \\
\text { terial não eléctrico) }\end{array}$ \\
\hline $311+312+313+314+315+316+321+322+323$ & & $\begin{array}{l}383 \text { (Indústrias de fabricação de ma- } \\
\text { terial eléctrico) }\end{array}$ \\
\hline $341+342+343+351+352+353+354+355$ & & $\begin{array}{l}384 \text { (Indústrias de construção de ma- } \\
\text { terial de transporte) }\end{array}$ \\
\hline $331+332+333+334+335$ & 38 & $\begin{array}{l}385 \text { (Indústrias de fabricação de ins- } \\
\text { trumentos profissionais) }\end{array}$ \\
\hline $362+363+364+365+366$ & 39 & $\begin{array}{l}390 \text { (Outras indústrias transforma- } \\
\text { doras) }\end{array}$ \\
\hline
\end{tabular}


d) Electricidade, Gás e Água

(d. Electricity, Gas and Water)

\begin{tabular}{|c|c|}
\hline CAE REV. 2 & CAE REV. 1 \\
\hline $401+402+403+410$ (excluindo 40302) & 4 (Electricidade, gás e água) \\
\hline
\end{tabular}

e) Construção Civil e Obras Públicas (e. Building Construction)

\begin{tabular}{|c|c|}
\hline CAE REV. 2 & CAE REV. 1 \\
\hline $451+452+453+454+455$ & 5 (Construção e obras públicas) \\
\hline
\end{tabular}

f) Serviços de distribuição - Comércio por Grosso e a Retalho (f. Trade)

\begin{tabular}{|l|l|}
\hline \multicolumn{1}{|c|}{ CAE REV. 2} & \multicolumn{1}{|c|}{ CAE REV. 1} \\
\hline $511+512+513+514+515+516+517$ & 61 (Comércio por grosso) \\
\hline $\begin{array}{l}501+503+504 \text { (excluindo 50402)+505+521+522+ 523+ } \\
+524+525+526\end{array}$ & 62 (Comércio a retalho) \\
\hline
\end{tabular}

g) Outros serviços de distribuição - Transportes, Armazenagem e Comunicações (g. Transports and communications)

\begin{tabular}{|l|l|}
\hline \multicolumn{1}{|c|}{ CAE REV. 2 } & \multicolumn{1}{c|}{ CAE REV. 1 } \\
\hline $601+602+603+611+612+621+622+623+711+712$ & 71 (Transportes, excluindo 719) \\
\hline $641+642$ & 72 (Comunicações) \\
\hline
\end{tabular}

h) Serviços de Apoio à Produção (h. Productive services)

\begin{tabular}{|c|c|}
\hline CAE REV. 2 & CAE REV. 1 \\
\hline $651+652+671$ & 81 (Bancos e outras Instituições financeiras) \\
\hline $660+672$ & 82 (Seguros) \\
\hline $\begin{array}{l}701+702+703+713+721+722+723+724+726+ \\
741+742+743+744+745+746+747+924\end{array}$ & $\begin{array}{l}83 \text { (Operações sobre imóveis e serviços } \\
\text { prestados às empresas) }\end{array}$ \\
\hline $631+632+633+634$ & $\begin{array}{l}719 \text { (Serviços relacionados com os transpor- } \\
\text { tes) }\end{array}$ \\
\hline 900 & 92 (Serviços de saneamento e limpeza) \\
\hline 014 & $\begin{array}{l}112 \text { (Serviços relacionados com a agricul- } \\
\text { tura) }\end{array}$ \\
\hline $731+732+911+912$ & $\begin{array}{l}932 \text { e } 935 \text { (Institutos Científicos, Associa- } \\
\text { ções e Organizações Profissionais) }\end{array}$ \\
\hline
\end{tabular}

i) Serviços Sociais e Administração Pública (i. Social and public services)

\begin{tabular}{|l|l|}
\hline \multicolumn{1}{|c|}{ CAE REV. 2 } & \multicolumn{1}{c|}{ CAE REV. 1 } \\
\hline $751+752+753$ & 91 (Administração Pública e Defesa Nacional) \\
\hline $801+802+803+804+851+852+853+913$ & $\begin{array}{l}93 \text { (Serviços sociais e similares prestados à } \\
\text { colectividade) excluindo 932 e 935 }\end{array}$ \\
\hline
\end{tabular}


j) Serviços Pessoais

(j. Personnal services)

\begin{tabular}{|l|l|l|}
\hline \multicolumn{1}{|c|}{ CAE REV. 2 } & & \multicolumn{1}{c|}{ CAE REV. 1 } \\
\hline $553+554+555$ & & 631 (Restaurantes, Cafés e similares) \\
\hline $551+552$ & 63 & $\begin{array}{l}\text { 632(Hotéis, pensões e outros locais de } \\
\text { alojamento) }\end{array}$ \\
\hline $\begin{array}{l}223+(2214)+714+748+921+922+923+9 \\
25+926+927\end{array}$ & 94 & (Serviços recreativos e culturais) \\
\hline $502+(50402)+527+725+930+950$ & 95 & (Serviços pessoais e domésticos) \\
\hline
\end{tabular}

A divisão 0 - Actividades mal definidas na CAE Rev. 1, não encontra paralelo na nova versão da CAE. Como a própria designação o indica, não a poderemos incluir especificamente em nenhuma das unidades classificativas, pois estas actividades terão, antes de mais, um carácter transversal a todas elas. No entanto, uma proposta será a de a classificar nos serviços pessoais e domésticos.

\section{ALGUMAS LIMITAÇÕES DA PROPOSTA APRESENTADA}

$\mathrm{O}$ primeiro problema que se levantou no presente trabalho relaciona-se com o nível de desagregação da informação comummente utilizada. Se considerarmos o nível de desagregação máximo (cinco dígitos na actual versão da CAE) a compatibilização é facilitada podendo-se seguir o trabalho do INE. Para a informação desagregada a três dígitos, levantam-se algumas questões que têm a ver com a estrutura conceptual patente na nova classificação. A inclusão de sub-ramos nos grupos anteriormente apresentados nem sempre foi fácil, pois muitas vezes estes representavam actividades que, na anterior versão da CAE, se distribuíam por sub-ramos diferenciados. Por outro lado, a referência a sub-ramos a um nível de desagregação superior a três dígitos reflecte não só essa dificuldade como também traduz as diferenças estrutural e conceptual entre as duas versões. Vejam-se os exemplos dos «metais ferrosos e não ferrosos» (275), cuja desagregação não é possível, o grupo correspondente à «reciclagem de desperdícios não metálicos» (372), que por nossa opção foi equiparado às «indústrias fundamentais» ou de fusão de vidro e a «reciclagem de sucata e de desperdícios metálicos» (371) que deverá ser dividida entre as «indústrias básicas de ferro e aço»e as «indústrias básicas de metais não ferrosos».

Estas são algumas das limitações desta proposta, que pensamos poderá servir de base para uma maior discussão àcerca da compatibilização da informação estatística disponibilizada pelos vários centros de difusão de informação. 


\section{BIBLIOGRAFIA}

Alves, Teresa; PIRES, Iva (1990) - Os serviços em Portugal. Evolução e distribuição regional 1960-1988. EPRU n ${ }^{\circ} 35$, CEG, Lisboa.

INE (1973) - Classificação das actividades económicas portuguesas por ramos de actividade. INE, Lisboa.

INE (1993) - Classificação portuguesa das actividades económicas: CAE - rev. 2. INE, Lisboa.

INE (1994) - Classificação portuguesa das actividades económicas: Tabelas de Equivalência. INE, Lisboa. 